August - 2004

\title{
A Comparative Study of Dropout Rates and Causes for Two Different Distance Education Courses
}

\author{
Christos Pierrakeas and Michalis Xenos \\ Hellenic Open University \\ Greece \\ Christos Panagiotakopoulos and Dimitris Vergidis \\ University of Patras Greece
}

\begin{abstract}
This paper reports the results of a survey conducted to examine the root causes leading to student dropout at a Greek distance education university. Data was gathered from two different courses an undergraduate course leading to a Bachelors degree in Informatics (characterized by high dropout rates), and a postgraduate course leading to a Masters degree in education (characterized by low dropout rates). A comparative analysis of these two different courses revealed important similarities in dropout percentages and the reasons cited by students for dropping out. Our analysis also revealed important differences as well. This paper presents the results of a survey designed to investigate the relationship between dropout with intrinsic (student-related) factors such as sickness, work/ school conflict etc., and extrinsic (institutional-related) factors such as study methods and materials, educational approach, and tutor influence.
\end{abstract}

Keywords: university level education; distance learning; dropout rates; dropout causes

\section{Introduction}

The establishment of open universities around the world aim to address the educational and reeducational needs of adult learners and workforce by providing a high level of studies (Evans and Lockwood, 1994, Evans and Nation, 1996). Open universities typically develop educational activities underpinned by an educational philosophy fundamentally different from those held by conventional educational systems. The main aspect of this philosophy is to promote "life long education" and to provide adults with "a second educational chance" (Keegan, 1993). The educational method used in an open university system is most typically "distance learning."

High student dropout rates have been reported in educational institutions using open and distance learning methods (Cardon and Christensen, 1998). Students dropout of their studies for a numerous reasons and factors (Eisenberg and Dowsett, 1990) ranging from academic, to nonacademic, to other factors (Jones and Watson, 1990). Factors include the degree of difficulty of courses and subjects selected by students; miscalculation of time students need to study (Sponder 1990); health problems (Kaye and Rumble, 1991); and family problems (Allen, 1994), to name a few. 
Dropout rates reported by open and distance learning (ODL) institutions are typically higher than those reported by conventional universities. Within ODL educational systems, dropout rates also vary depending on the educational system adopted by each institution and selected subjects of study (Narasimharao, 1999). In Europe, dropout rates in distance education programs typically range from 20 percent to 30 percent (Rumble, 1992) or even higher in Northern America (Schlosser and Anderson, 1994). Asian countries have recorded rates as high as 50 percent (Shin and Kim, 1999; Narasimharao, 1999). A number of models, such as Tinto's model of student retention, (Bernard and Amundsen, 1989), have been developed to help explain the dropout phenomenon in higher education.

\section{Purpose}

The purpose of this study is to investigate the factors and root causes leading student dropout. It is felt that our research will enable staff working in ODL institutions to "identify" high and at risk students and student groups (e.g., individual students or entire student groups more likely to dropout than other students/ students groups). It is felt that our research will enable student support staff at the Hellenic Open University, as well as staff at other universities offering open and distance learning, to deal with high-risk groups more efficiently and effectively, thereby minimizing student dropout.

The research questions examined in this paper are:

- To what extent is student dropout due to intrinsic (related to the student) factors and to what extent is it due to extrinsic (non-student) factors? (e.g., study methods and materials)

- To what extent does actively taking part in optional components of the educational process lead students to interrupt their studies?

- To what extent do the educational materials and/ or tutors lead students to withdraw from their studies?

- Are there any similarities/ differences in dropout rates/ causes on different courses? And at what level would these be?

\section{Objective}

The objective of this study is to examine the "reasons why" students enrolled in two different distance education programs of study opted to dropout.

\section{Sample}

The sample was drawn from students enrolled in two academic programs offered by the Hellenic Open University: 1) a two-year Bachelors degree in Informatics program; and 2) a two-year Masters degree in Education. Students enrolled in the Bachelors of Informatics program was comprised of undergraduate students (i.e., high school graduates). Students enrolled in the Masters degree in Education was comprised of graduate students (e.g., Bachelor's prepared teachers and teacher-trainees). 


\section{A Comparative Study of Dropout Rates and Causes for \\ Two Different Distance Education Courses \\ Pierrakeas, Xenos, Panagiotakopoulos \& Vergidis}

The Bachelors degree in Informatics and the Masters degree in Education were selected to ensure that both undergraduate and graduate students, studying both technologies and the social sciences, were represented in our sample. These two academic programs are also the most popular offered by the Hellenic Open University, and therefore are of high importance to the University.

\section{Overview}

A broad overview of the Hellenic Open University (HOU) is presented here to inform readers about the institution's operational practices. The HOU uses a modular system, with modules of one academic year comprising its basic functioning unit. Each module is comprised of three or four conventional university-level subjects, depending on the subjects' degree of difficulty. Similar educational set-ups and programs are offered by other open universities (Lupo and Erlich, 2001), so HOU's approach to distance education is not new or novel. HOU's educational material is comprised mainly of printed material supplemented with audio-visual and/ or electronic material. Each HOU tutor oversees the learning progress of approximately 30 students. To earn an undergraduate degree, undergraduate students must successfully complete 12 modules (four academic years); to earn a postgraduate degree, graduate students are required to successfully complete four modules (two academic years).

For each module, students must complete four to six written assignments (30 percent of the final grade) and to sit for a final exam (70 percent of the module's final grade). HOU students enrolled in these courses have the option of participating in four to six group-counseling (face-to-face) meetings that take place at their residence or at a convenient location nearby.

\section{Findings and Discussion}

In 2000 - 2001, 510 students were enrolled in the "Informatics" course. The following academic year, 2001-2002, student enrollment in this course increased to 720. During their first year of studies, students enrolled in the Informatics degree program have the choice of registering two of three modules: a.) Introduction to Informatics (INF10); b.) Introduction to Software Engineering (INF11); and c.) Mathematics I (INF12). The student handbook, however, strongly advises students to include INF10 in their module selection. As a result, 97.7 percent of the $2000-2001$ students $(n=498)$, and 99.7 percent of the $2001-2002$ students $(n=718)$ specifically elected this module - INF10.

In the 1999 - 2000 academic year, the total number of students enrolled in "Studies in Education" was 1,220. This course consists of the following modules: a.) Open and Distance Learning Education (SED01) ( $n=758$ / 62.13 percent of the total students enrolled); b.) Adult Education (SED02) ( $n=105 / 8.61$ percent); c.) The Child's Development in the Social Environment (SED03) ( $n=196 / 16.07$ percent); d.) Administration of Educational Units (SED04) $(n=113$ / 9.26 percent); and e.) Educational Research in Action (SED05) ( $n=48$ / 3.93 percent).

Students have the option of choosing any of the aforementioned module combinations, so long as they do not exceed the module limit per academic year. Table 1 below illustrates the total number of students enrolled in both the Bachelors of Informatics and the Masters of Education degree programs. Please note the low percentage of female students enrolled in the Informatics courses. 
Table 1. Total number of students enrolled in Bache lors of Informatics and Masters in Education degree programs

\begin{tabular}{|c||c|c||c|c|}
\hline \hline & \multicolumn{2}{c||}{ Informatics } & \multicolumn{2}{c|}{ Studies in Education } \\
& $\mathrm{N}$ & $\%$ & $\mathrm{~N}$ & $\%$ \\
\hline \hline Male & 873 & 71.0 & 577 & 47.3 \\
\hline \hline Female & 357 & 29.0 & 643 & 52.7 \\
\hline \hline Total & 1,230 & 100.0 & 1,220 & 100.0 \\
\hline \hline
\end{tabular}

\section{Method}

A descriptive research design was used for this survey; three different sources were used for data collection. The first source of data came from HOU's student registry records, which contain demographic data routinely collected during registration (e.g., student's age, sex, previous education, family status, etc.) along with the number and types of courses selected by each student for each study model. The second source of data came from tutors' class records (e.g., number of students who attended the optional face-to-face meetings and grades recorded on students' assignments). The majority of tutors responded to the survey, therefore we were able to gather relevant data on 89 percent of the students enrolled in the two courses under study. This percentage guarantees statistical validity of results (Anastasi and Urbina, 1997). The third source of data came from short structured interviews, which were conducted with (most) student dropouts at the end of each term. These structured interviews were designed to gather qualitative information about the "reasons" why students' elected to dropout of their studies. During these short interviews, students were also asked their opinions about their tutors' performance, course material used, and about the HOU in general.

Data collected from the first and second sources came directly from HOU's Student Registry records and tutors' class records. Data from the third source came from answers collected from structured interviews; these interviews were typically two to five minutes in duration. Student dropouts were asked a set of structured open-ended questions in a prearranged order. They were asked their opinions on four major issues related to their studies: a.) their reason(s) for dropping out of their studies; b.) their opinion about their tutors' performance; c.) their opinion about the educational materials used; and d.) their opinion about HOU in general. Upon completion of each interview, each answer was transcribed, and subjected to content analysis in order to categorize students' responses. All data was analyzed using multivariate methods (Anastasi and Urbina, 1997) as well as correlation analysis associating the factors that were examined. The main statistical tests used to check the correlation between variables were x2-test and Spearman rank order correlation coefficient. The resulting correlations and differences between variables were assumed statistically significant (Anastasi and Urbina, 1997; Siegel and Castellan, 1988).

Of 173 students who dropped out of "Studies in Education," 108 (62.4 percent) participated in this study. For a more detailed study on this group's profile, please refer to Vergidis and Panagiotakopoulos (2002). Of the 349 students who dropped out of "Informatics," almost the entire dropout student population (97 percent) was interviewed. For a detailed study regarding this group's profile, please refer to Xenos, Pierrakeas, and Pintelas (2002). The remaining student 
dropouts had moved residence, could not be located, or had refused to participate and are thus not included in the data.

\section{Student Dropout Rates}

Of the 1,230 undergraduate students enrolled in the "Informatics" course, 349 dropped out (28.4 percent). Of the 349 undergraduate students dropouts, 338 (96.8 percent) took part in our study. Of the 1,220 graduate students enrolled in the course "Studies in Education," 173 dropped out (14.2 percent). Of the 173 graduate students who had dropped this course, 108 (62.4 percent) took part in our study.

The above dropout rates include those students enrolled in at least one module, but failed to deliver one project (e.g., a written assignment), had elected not to re-register in HOU, and indicated they would not re-enroll in HOU at a future date. Dropout rates also included students enrolled in multiple courses, who had successfully completed some but not all of their assignments, and had indicated they would not re-enroll in HOU at a future date.

The dropout rates described above also include those students who did not complete some or all of their assignments, but indicated they would continue their studies at HOU, by repeating these modules the following year. Along with the above, the data in Table 2 also include those students who successfully completed all their assignments in all the selected modules.

Table 2. Dropout and completion rates of students enrolled in Informatics and Studies in Education.

\begin{tabular}{|c||c|c||c|c|}
\hline \hline & \multicolumn{2}{|c||}{ Informatics } & \multicolumn{2}{c|}{ Studies in Education } \\
\hline \hline & $\mathrm{N}$ & $\%$ & $\mathrm{~N}$ & $\%$ \\
\hline \hline Dropout & 349 & 28.4 & 173 & 14.2 \\
\hline \hline Continue & 881 & 71.6 & 1,047 & 85.8 \\
\hline \hline Total & 1,230 & 100.0 & 1,220 & 100.0 \\
\hline \hline
\end{tabular}

\section{Student Dropouts in Relation to Student Profiles}

According to the existing legal framework for the HOU, individuals aged 23-45 have priority to enroll. Students who dropped out from "Studies in Education" mainly belong to the 35-39 age group (30 percent of the total) and to the 30-34 age group (27 percent of the total) as shown in Table 3. Fifty-seven percent of those students who dropped out are between age 30-39, and are, therefore, at their most productive age. 
Pierrakeas, Xenos, Panagiotakopoulos \& Vergidis

Table 3. Student Dropout Rates by Age Group

\begin{tabular}{|c||c|c||c|c|}
\hline \multicolumn{1}{|c||}{} & \multicolumn{2}{c||}{ Informatics } & \multicolumn{2}{c|}{ Studies in Educ ation } \\
\hline \hline Age & N & $\%$ & N & $\%$ \\
\hline \hline$<30$ & 119 & 35.2 & 21 & 19.4 \\
\hline \hline $30-34$ & 128 & 37.9 & 29 & 26.8 \\
\hline \hline $35-39$ & 66 & 19.5 & 33 & 30.6 \\
\hline \hline$>39$ & 25 & 7.4 & 25 & 23.2 \\
\hline \hline Total & 338 & 100.0 & 108 & 100.0 \\
\hline \hline
\end{tabular}

It is worth noting that in both courses surveyed, 57.4 percent of students dropouts are from the 30-39 age group - typically a period of one's life that is quite demanding in terms of balancing occupational obligations and family responsibilities. Differences have also been observed among other age groups as well. The percentage of dropouts is higher with younger students $(<30)$ enrolled in the undergraduate course "Informatics" as opposed to being quite low (7.9 percent) with older students (>39). One likely explanation for this phenomena is that that younger students $(<30)$ are typically studying for the first time, and hence have little or no previous experience of studying at the university level. As such, these students are more likely to underestimate the effort and workload required of university level studies. Moreover, many of these students do not possess the background knowledge to cope with the demands of their studies. Bearing in mind these factors, along with occupational obligations and family responsibilities, withdrawal from studies is understandable for this age group.

The data collected on students who dropped out of the postgraduate course, "Studies in Education," revealed that older students $(>39)$ tended to drop out of their studies. Whereas younger students $(<35)$, having recently gained experience in university level studies, are more familiar with the rigors of study, and therefore tended to be more conscientious, try harder, and study "smarter." Older students (>35), however, are typically more entrenched in their current professional path, which makes it easier for them to dropout if they feel that their education is interfering with their professional responsibilities.

Table 4. Student Dropout Rates and Gender

\begin{tabular}{|c|c|c|c|c|}
\hline & \multicolumn{2}{|c|}{ Informatics } & \multicolumn{2}{|c|}{ Studies in Education } \\
\hline & N & $\%$ & $\overline{\mathrm{N}}$ & $\%$ \\
\hline Male & $\overline{238}$ & 70.4 & 52 & $\overline{48.1}$ \\
\hline Female & $10 \overline{0}$ & 29.6 & 56 & 51.9 \\
\hline Total & $\overline{338}$ & 100.0 & 108 & 100.0 \\
\hline
\end{tabular}


Table 4 shows the distribution of student dropout rates by gender. For "Studies in Education," females consist of 52.7 percent of the sample, and the 51.9 percent of the dropouts $\left(x^{2}=0.8, D F=1\right.$, NS). Similar results were found for "Informatics" students, in which females consist of the 29.0 percent of the sample, and the 29.69 percent of the dropouts $\left(x^{2}=0.4, D F=1\right.$, NS). Considering that differences for both programs of studies are not statistically significant, the correlation between dropouts and gender shows that the overall dropout rates are similar in men and women.

Table 5. Working Status of Students who Dropout

\begin{tabular}{|c||c|c||c|c|}
\hline \hline & \multicolumn{2}{c||}{ Informatics } & \multicolumn{2}{c|}{ Studies in Education } \\
\hline \hline & $\mathrm{N}$ & $\%$ & $\mathrm{~N}$ & $\%$ \\
\hline \hline Employed & 320 & 94.7 & 107 & 99.1 \\
& & & & 0.9 \\
\hline \hline Unemployed & 18 & 5.3 & 1 & \\
\hline \hline Total & 338 & 100.0 & 108 & 100.0 \\
\hline \hline
\end{tabular}

Table 5 shows that all students who had dropped out - with the exception of one - were presently employed at the time of this study. Only one student (female) stated that she was unemployed. Bearing in mind that the percentage of unemployed students within the total number of students attending the "Studies in Education" course is 2.1 percent, we concluded that the dropout rates are similar (not statistically significant) in employed and unemployed students.

Similar conclusions can be made regarding the relationship between student dropouts and students' working status within the "Informatics" course, where 5.3 percent of student dropouts claimed they were unemployed, while the overall percentage of unemployed students was 4.1 percent. Considering the derived differences for both programs of study are not statistically significant, the correlation between student dropouts and students' working status shows that the overall dropout rates are similar (not statistically significant) between employed and unemployed students.

Table 6. School Teachers and Non-School Teachers who Dropped Out

\begin{tabular}{|c||c|c|}
\hline \hline & \multicolumn{2}{|c|}{ Studies in Education } \\
\hline \hline & N & $\%$ \\
\hline \hline Teachers & 83 & 77.6 \\
\hline \hline Non teachers & 24 & 22.4 \\
\hline \hline Total & 107 & 100.0 \\
\hline \hline
\end{tabular}

It is not surprising that graduate students enrolled in "Studies in Education," would mainly comprise of Bachelor's prepared school-teachers. Referring to Table 6, we can draw the 
conclusion that of the high percentage of student dropouts (22.4 percent as compared to 14.2 percent, which is the mean average), roughly half of those who elect to dropout are not teachers. Of those students who are employed, school-teacher dropouts comprised a much lower percentage compared to those dropouts employed in other professions or jobs. This phenomena may be explained by that fact that school-teachers enrolled in this courses tend to be more familiar with studying and essay writing, they tend to have more free time compared to other working students, they are more motivated because of their professional standing, and/ or because they are more familiar with pedagogy given their hands-on experience in the classroom.

Table 7. Student Dropout Rates versus Current Professions

\begin{tabular}{|c||c|c|}
\hline \hline & \multicolumn{2}{|c|}{ Informatics } \\
\hline \hline Related to informatics & 188 & 58.8 \\
\hline \hline Not related to informatics & 132 & 41.2 \\
\hline \hline Total & 320 & 100.0 \\
\hline \hline
\end{tabular}

Table 7 illustrates the correlation between dropouts and students' working involvement in professional activities related to Informatics. The high percentage (41.2 percent) of dropout students whose professional activity/ work was not related to Informatics indicates the statistically significant correlation between student dropouts and involvement of students in activities directly or indirectly related to Informatics $(\mathrm{R}=0.428, \mathrm{p}<0.0001)$. Obviously a profession indirectly or directly related to Informatics (e.g., being an avid computer user, programmer, or technician) provides these students with a significant amount of tacit background knowledge, which typically augments their learning. Furthermore, they can put their academic knowledge into action in their daily working life (e.g., interacting on a professional level with their work colleagues and peers).

\section{Student Dropout Rates in Relation to Educational Procedures Used}

The purpose was to determine the degree of dropout students' participation in the educational processes of the HOU, to figure out at what stage students tended to dropout of their studies. As we can see in Table 8, 51.8 percent of our sample had failed to deliver any assignment, and 27.8 percent had completed only one assignment. This finding reveals that 80 percent of dropout students had quit studying from the outset, a finding which supports results from previous research (Holmberg, 1995). Sixteen percent of the sample, however, dropped out after having completed two written assignments, while some discontinued prior to final exams, although they had completed all their written assignments. 
Pierrakeas, Xenos, Panagiotakopoulos \& Vergidis

Table 8. Dropout Rates versus Total Number of Written Assignments Completed

\begin{tabular}{|c|c|c|c|c|}
\hline & \multicolumn{2}{|c|}{ Informatics } & \multicolumn{2}{|c|}{ Studies in Education } \\
\hline $\begin{array}{l}\text { Nurnber of handed-in } \\
\text { written assiguments }\end{array}$ & $\bar{N}$ & $\%$ & $\mathrm{~N}$ & $\%$ \\
\hline 0 & 94 & 27.8 & 56 & 51.8 \\
\hline 1 & 155 & 45.8 & 30 & 278 \\
\hline$\overline{2}$ & $\overline{52}$ & 15.4 & 18 & 16.7 \\
\hline$\overline{3}$ & 29 & 8.6 & 3 & 22.8 \\
\hline$\overline{4}$ & 8 & 2.4 & 1 & 0.9 \\
\hline Total & 338 & 1000 & 108 & 100 \\
\hline
\end{tabular}

The Informatics course yields similar results, as shown in Table 8, which shows that 73.6 percent of the students who had elected to dropout had only handed-in none or only one written assignment.

These results suggest that that having handed in half of the required written assignments makes it harder for most students to dropout. Thus, 3.0 percent of such students dropped out from the Informatics course, and only 0.3 percent dropped out from the Studies in Education course (both percentages are drawn from the overall number of students).

It can be concluded, therefore, that for students enrolled in Studies in Education, the majority of dropouts belonged to the 30 - 39 age group, and most are employed. In addition, gender does not appear to play in role in student dropout of these two courses, as revealed in our data which shows no significant statistical difference. For student dropouts who are employed, schoolteachers represented a much lower percentage in comparison to the students working in other professions or jobs. Finally, most student dropouts take place at or near the beginning of the module (up to the point of submission of the second written assignment).

For students enrolled in "Informatics" modules, we can conclude that the vast majority of student dropouts belong to the 30-39 age group, almost all are employed, and gender does not appear to be a factor in student dropout. Similar to students enrolled in the Studies in Education modules, those enrolled in the Informatics modules tended to dropout at the start of their studies, at a period prior to handing in their second written assignment. Interesting comparisons can also be made between Informatics student dropout rates and Studies in Education dropout rates. The percentage of student dropouts below age of 30, and the percentage of those whose profession is not associated with Informatics, are double as compared to the analogous numbers drawn from the Studies in Education course.

\section{Causes of Student Dropout}

No entry exams are required in order to register in the Hellenic Open University. To gain entry, all that is required is that prospective students complete an application form, after which a draw may take place in instances where demand is high versus actual spaces available. Courses are not 


\section{A Comparative Study of Dropout Rates and Causes for \\ Two Different Distance Education Courses \\ Pierrakeas, Xenos, Panagiotakopoulos \& Vergidis}

free, as is the case Greece's conventional universities. Students must also pay part of their student fees and tuition in advance. Therefore, it could be safely assumed that students enrolled in HOU have programmed their studies prior to enrolling and have, indeed, chosen their subject of preference.

From the above, it can be safely assumed that the main cause for dropping out would stem from unexpected/ emergency situations encountered by these students. Another root cause leading to dropout, however, seems to stem from students' initial understanding in terms of the underestimating of the time and effort needed for effective study.

In sum, the reasons for students dropping out of their studies can be grouped into four main categories: 1) professional; 2) family/ personal; 3) health; and 4) academic.

a) Professional reasons (Profess) relate to students' underestimation of the time required to balance their academic and professional obligations. This category also encompasses major changes that occur in students' work life (i.e., work transfer or promotion).

b) Family and personal reasons (Fam-Per) relate to marriage, pregnancy, childbirth, childrearing, travel problems, death of a family member, separation and/ or other personal reasons (some of which students' are not willing to discuss with the interviewer).

c) Health reasons (Health) relate to personal health issues or family health challenges (i.e., parent's, husband's, wife's, sibling's, child's illness).

d) Academic reasons were divided into two sub-categories: Acad1 and Acad2. Acad1 relate to lack of assistance from tutors (real or perceived), improper learning materials/ teaching methods used, and/or students' inability to understand the course learning material sufficiently to satisfy minimum academic obligations on written assignments. Acad2 relates to students who admit that they lacked adequate prerequisite knowledge (for a specific course) to pursue university-level studies and had to drop out as a direct result, wrong choice of the program, or found they had no interest in the topic.

Table 9. Reasons Cited by Students for Dropping Out

\begin{tabular}{|c||c|c||c|c|}
\hline \hline & \multicolumn{2}{|c||}{ Informatics } & \multicolumn{2}{c|}{ Studies in Education } \\
\hline \hline Reasons & $\mathrm{N}$ & $\%$ & $\mathrm{~N}$ & $\%$ \\
\hline \hline Frofess & 150 & 43.0 & 50 & 46.3 \\
\hline \hline Fam-Per & 64 & 18.3 & 29 & 26.8 \\
\hline \hline Health & 24 & 69 & 12 & 11.1 \\
\hline \hline AcadI & 44 & 12.6 & 9 & 8.3 \\
\hline Acad2 & 67 & 19.2 & 8 & 7.4 \\
\hline \hline
\end{tabular}




\section{Professional (Profess)}

Reasons for dropping out outlined in Table 9, comprise 47 percent of Studies in Education, and 43 percent Informatics respectively for students who dropped out due to professional reasons. Academic workload versus occupational demands constitutes an urgent and unpredictable factor. Upon closer examination, however, reasons cited by students for dropping out tend to stem from their erroneous evaluation of the amount of time they actually have available to study versus what is needed. Studies at the HOU require hard work and students must devote plenty of time to studying - realistic academic demands that many student dropouts fail to realize prior to enrolling.

\section{Family-Personal (Fam-Per)}

The Family-Personal category includes reasons such as marriage, divorce, childrearing, pregnancy, socio-economic problems, and other related factors. Reasons cited by student dropouts in this case are "not unexpected" factors that led them to abandon their studies. To a great extent such changes are typical events that occur in adults' everyday lives - some of which that nonetheless have immediate consequences that affect their everyday routine and thus upset their academic plans.

Twenty-seven percent of the Studies in Education sample, and the 18 percent of the Informatics sample, indicated they elected to dropout owing to family reasons that altered their daily routines, and which did not allow them to attend to their studies. Similar to the "Professional" reasons cited above, these students' miscalculated their time available to balance their academic and family obligations. A significant percentage of those student dropouts surveyed indicated that they gave up on their studies because they had not taken into account the impact their academic commitments would have on their personal lives (i.e., the reduction of time available for their family versus what they needed to be successful students).

Health problems are also included in Personal category of unexpected events that led students to abandon their studies. Eleven percent of student dropouts in Studies in Education students, and seven percent in Informatics, cited health complications as their primary reason leading to their decision to discontinue their studies. As such, there are truly "unexpected" events independent from the students' programming and their studies at the Hellenic Open University.

\section{Academic (Acad1 / Acad2)}

The Academic category is directly related to students' experiences with their studies. Sixteen percent of student dropouts in Studies in Education, and 32 percent of those enrolled in Informatics, indicated they elected to discontinue their studies for academic reasons. Due to the significance of this category, the reasons cited by student dropouts are presented in detail. Fortyseven percent cited erroneous course selection, which they indicated as being of no professional interest or value. In sum, it was the students" "wrong choice" that led to their decision to discontinue their studies.

Twenty-eight percent admitted they were not qualified enough (did not have the required knowledge for the specific course) to pursue university-level studies, which thereby compelled 


\section{A Comparative Study of Dropout Rates and Causes for \\ Two Different Distance Education Courses \\ Pierrakeas, Xenos, Panagiotakopoulos \& Vergidis}

them to dropout. Thirty-eight percent indicated that the method of studying as the reason why they elected to give up on their studies.

Difficulty of the educational material was cited as the reason for dropping out by 13 percent. Student evaluation of the educational material is essential in distance learning settings. Student dropouts' opinions of the educational material used, therefore, is of great importance to HOU, as they represent those students who "did not make it." HOU's aim therefore is to determine "why" these students did not make it. Although students who dropout cannot - or should not - dictate the difficulty levels of course materials on offer, their opinions can be used to develop more intuitive learning materials to help them learn and comprehend difficult topics and subjects. Twenty percent of this sub-sample found the educational material very difficult or difficult.

Nine percent claimed that although they were able to understand the course materials, they could not fulfill their obligations related to the written assignments, thus compelling them to dropout.

When asked about their opinion about the tutor, the vast majority of dropouts (82 percent) indicated that they had no problems with their tutor, and felt they were offered all the assistance possible. The remaining 18 percent indicated they had some problems with their tutor. Of this 18 percent who cited problems with their tutor, 23 percent mentioned communication problems (i.e., slow response time to their letters, difficulty to reach by telephone, etc.); 40 percent cited tutors' lack of assistance in helping them understand assigned materials and written assignments; seven percent claimed that their tutor did not convince them they had the required knowledge to continue; five percent claimed the tutor not communicate well during face-to-face meetings. Another 9.5 percent cited lack of assistance from their tutors (or less assistance than was expected by the student).

It is worth noting that although the HOU is a newly established institution, 95 percent of the student dropouts surveyed feel that the University meets important social needs of the Hellenic/ Greek community, and as a consequence they hold positive opinions of HOU. When asked to comment on why they dropped out of their studies, and give their opinion on the studies offered by the HOU, 67 percent of the student dropouts indicated that Hellenic Open University courses are very well organized, but for various reasons (not related to their studies or tutors) they felt that they could not continue. Fourteen percent of those who dropped out felt that the education offered is useful, but it is aimed at students that are working with, or in some way related, to the subject of the studies. Eighteen percent believe that significant improvements should be made to the quality of the studies offered. Finally, two percent held negative opinions of the education offered by the Hellenic Open University.

\section{Conclusion}

The study of these two different courses targeting two distinct groups of students - undergraduate and graduate - revealed considerable similarities in terms of dropout percentages, and underlying reasons that compelled them to interrupt/ discontinue their studies. There were important differences as well, however.

Gender does not appear to have a significant role in compelling students to interrupt/ discontinue their studies in both groups, including those dropouts age 30-39 who are the most vulnerable because they face the daily challenge of balancing family and/ or work issues with their education. There is no statistical significant difference between employed and unemployed 


\section{A Comparative Study of Dropout Rates and Causes for Two Different Distance Education Courses \\ Pierrakeas, Xenos, Panagiotakopoulos \& Vergidis}

students, although most are employed (most distance learning students are employed). Finally, students enrolled in Informatics and Studies in Education, both tend to dropout at the second written assignment phase.

Lessons that can be learned from the data presented here is that DE tutors should first recognize which students/ student groups are most vulnerable to dropping out (e.g., students age 30-39), and secondly, encourage and support these vulnerable students/ student groups by paying close attention to their needs during the first half of the academic year (up until the second written assignment has been successfully delivered). Clearly, tutors should provide support and encouragement to all students irrespective of the course they teach, but sensitivity to a particular vulnerable student or student group should also be a priority for tutors.

For comparison between the Informatics course and the Studies in Education course, in the Informatics course there are twice as many dropouts in the overall number of students enrolled, twice as many dropouts age 30 or younger, and twice as many dropouts whose profession/ employment situation is not related to informatics, as compared to the analogous percentages calculated for Studies in Education.

This finding reveals that the overall anticipated percentage of student dropouts tend to be much higher in undergraduate courses as compared to postgraduate courses. This may be explained by the fact that undergraduate students typically lack university-level academic experience. This finding also reveals that students' professional standing (e.g., exposure/ personal interest in the field or actual work experience) is highly relevant at the undergraduate level and mitigates against dropout. On the other hand, this factor does not seem to hold much importance when it comes to postgraduate level studies.

The findings also suggest that tutors should encourage and support undergraduate students age 30 and under, and those who are over age 39 at a postgraduate level. Support and encouragement is likewise crucial at both levels for students in the 30-39 age group for the aforementioned reasons. These findings suggest that undergraduate students, age 30 and younger, and may not appreciate the time and effort needed for successful study. Graduate students, on the other hand, age 30 or younger, by virtue of their previous academic experience (and arguably their desire to succeed professionally and academically) are intensely aware of the effort required, and therefore they are not as vulnerable as similarly aged undergraduate students.

There were similarities concerning the numbers of students who elected to drop out because of family, personal, or health reasons. Such reasons, relate to childbirth, child rearing, marriage, pregnancy, travel problems, decease of a family member, and other personal reasons (some of which the students were not willing to discuss) or reasons related to personal or familial health problems.

According to the respondents, the most significant reasons they cited for dropping-out stems from their underestimation of the actual time they have available for studying versus their other obligations, and/or unforeseen changes in their daily/ work environment (e.g., promotion, travel, transfer, pregnancy, death) that affected their ability to continue with their studies. This phenomenon is more evident undergraduate level where students typically possess little or no previous experience in university level studies. At postgraduate level however, where previous academic experience is present, dropout numbers are significantly lower. 
According to the data collected, the educational materials used and interaction with tutors did not seem to make things so difficult for students, as to lead them to dropout of their studies. Only a small percentage cited tutors or educational materials as the reason for dropping out.

Overall, those students who elected to drop out of their studies, tend to regard the educational offerings of Hellenic Open University as positive. They see the studies offered by Hellenic Open University as well organized and the education useful.

\section{Acknowledgements}

The authors would like to thank the students, tutors, and personnel of Hellenic Open University for their assistance in our research.

\section{References}

Allen, B. (1994). The Student in Higher Education: Nontraditional Student Retention CATALYST, 23(3), $19-22$.

Anastasi, A., and Urbina, S. (1997). Psychological testing. Englewood Cliffs, NJ.: Prentice-Hall.

Bernard, R., and Amundsen, C. (1989). Antecedents to Dropout in Distance Education: Does one model fit all? Journal of Distance Education, 4(2), 23 - 46.

Cardon P., and Christensen, K. (1998). Technology-Based Programs and Drop-Out Prevention. The Journal of Technology Studies. Retrieved on June 9, 2004 from: http://scholar.lib.vt.edu/ejournals/JTS/Winter-Spring-1998/cardon.html

Eisenberg, E., and Dowsett, T. (1990). Student Dropout from a Distance Education Project Course: A new method analysis. Distance Education, 11(2), 231 - 253.

Evans, T., and Lockwood, F. (1994). Understanding Learners in Open and Distance Education. London: Kogan Page.

Evans, T., and Nation, D. (Eds.) (1996). Opening Education: Policies and practices from open and distance learning. London: Routledge.

Jones, D. J., and Watson, B. C. (1990). “High Risk” Students and Higher Education: Future frends, ERIC Document No. ED 325033.

Holmberg, B. (1995). Theory and Practice of Distance Education. New York: Routledge.

Kaye, T., and Rumble, G. (1991). Open Universities: A Comparative Approach, Prospects, 21(2), $214-216$.

Keegan, D. (1993). Theoretical Principles of Distance Education. London: Routledge.

Lupo, D., and Erlich, Z . (2001). Computer literacy and applications via distance e-learning. Computers \& Education, 36(1), 333 - 345. 
Narasimharao, B. (1999). Issues in preparing Open University learners for Open University system. The Commonwealth of Learning Educational Media Centre for Asia website. Retrieved June 9, 2004 from: http://www.cemca.org/ignou-icde/paper23.html

Rumble, G. (1992). The Management of Distance Learning Systems. Paris: UNESCO / IIEP.

Schlosser, C. A., and Anderson, M. L. (1994). Distance Education: Review of the literature. Washington, DC.: Association for Educational Communications and Technology.

Shin, N., and Kim, J. (1999). An exploration of learner progress and drop-out in Korea National Open University. Distance Education, 20(1), 81 - 95.

Siegel, S., and Castellan, N. J. (1988). Measures of Association and Their Tests of Significance. Nonparametric statistics for the behavioral sciences. (2nd ed.) New York: McGraw-Hill.

Sponder, B. (1990). Distance Education in Rural Alaska: An overview of teaching and learning practices in audioconference courses. Center for Cross-Cultural Studies. Fairbanks, AK.: Alaska University,

Vergidis, D., and Panagiotakopoulos, C. (2002). Student Dropout at the Hellenic Open University: Evaluation of the graduate program "Studies in Education.” International Review of Research in Open and Distance Learning, 3(2). Retrieved July 30, 2004 from: http://www.irrodl.org/content/v3.2/vergidis.html

Xenos, M., Pierrakeas, C., and Pintelas, P. (2002). A Survey on Student Dropout Rates and Dropout Causes Concerning the Students in the Course of Informatics of the Hellenic Open University”, Computers \& Education, 39(4), 361 - 377.

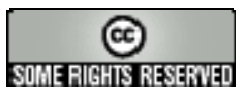

